3. Beger, O., et al., Anatomy of the Anterior Clinoid Process in Human Fetuses. J Craniofac Surg, 2020. 31(5): p. 1469-1473

4. Dagtekin, A., et al., Microsurgical anatomy and variations of the anterior clinoid process. Turk Neurosurg, 2014. 24(4): p. 484-93.

5. da Costa, M.D.S., et al., Anatomical Variations of the Anterior Clinoid Process: A Study of 597 Skull
Base Computerized Tomography Scans. Oper Neurosurg (Hagerstown), 2016. 12(3): p. 289297.

6. Evans, J.J. and T.J. Kenning, Craniopharyngiomas: Comprehensive Diagnosis, Treatment and Outcome. 2014: Elsevier Science.

\title{
CÁC YẾU TỐ ẢNH HƯỞNG ĐẾN KẾT QUẢ ĐIỀU TRI LASER TẠO HÌNH VÙNG BÈ CHỌN LOQC TRÊN BÊ̂NH NHÂN GLÔCÔM GÓC MỞ ĐÃ ĐƯợC ĐIỀU TRI THUỐC TRA HẠ NHÃN ÁP
}

\author{
Đỗ Tấn ${ }^{1}$, Phạm Thị Thu Thủy², Nguyễn Đức Thịnh²
}

TÓM TẮT

Mục tiêu: Nhận xét một số yếu tố liên quan đến kết quả điều trị tạo hình vừng bè chọn lọc bằng laser trên bệnh nhân glôcôm góc mở đã được điêuu trị thuốc tra hạ nhãn áp. Đối tượng phương pháp nghiên cứu: nghiên cứu mô tả trên 40 mắt của 28 bênh nhân glôcôm góc mở nguyên phát và thứ phát do thuốc đã tra thuốc ha nhãn áp, được tao hình vùng bè chọn loc bằng laser $360^{\circ}$. Tình trạng thị lực, thị trường, nhã̉n áp, góc tiền phòng, đáy mắt, thông số laser, số thuốc tra được đánh giá tại các thới điểm trước và sau điều trị 2 tuần, 1 tháng, 3 tháng. Kết quả: Có mối liên quan giữa giới tính, tình trạng sắc tố vùng bè, nhãn áp trước điểu trị và thành cồng điều tri. Tai thới điểm 2 tuần bệnh nhân nam có tỷ lệ thành công cao hơn bênh nhân nữ $(p=0,013)$. Tai thời điểm 3 tháng sắc tố vùng bè càng cao càng làm tăng mức độ thành công điêu trị $(p=0,017)$. Tại thời điểm 1 tháng nhãn áp trước điều trị càng cao càng làm tăng mức đô thành công điều trị $(p=0,013)$. Không tìm thấy mối liên quan có ý nghĩa thống kê giữa tuổi, thời gian mắc bênh, số thuốc tra hạ nhãn áp trước điếu trị, giai đoạn bểnh, năng lượng laser đến thành công của điêuu trị. Kết luận: Có mối liên quan có ý nghĩa giữa giới tính, sắc tố vùng bè, nhãn áp trước điều trị với tỷ lệ thành công của điêu trị

Tư khóa: Glốcôm góc mở, laser tạo hình vùng bè, thuốc hạ nhãn áp

\section{SUMMARY}

\section{IMPACTING FACTORS FOR OUTCOME OF} SLT ON MEDICALLY TREATED OAGs

Objective: To evaluate some impacting factor for SLT effectiveness on POAG eyes which was already treated with IOP lowering medications. Patients and Methods: Descriptive study on 40 eyes of 28 POAG and steroid-induced patients on IOP lowering

${ }^{1}$ Bệnh Viện Mắt Trung Ương

${ }^{2}$ Đai Hoc Y Hà Nôi

Chịu trách nhiệm chính: Đỗ Tấn

Email: dotan20042005@yahoo.com

Ngày nhận bài: 13.01.2021

Ngày phản biên khoa hoc: 11.3.2021

Ngày duyệt bài: 22.3.2021 medications who have been treated with $360^{\circ} \mathrm{SLT}$. VA, VF, IOP, gonioscopy, optic disc, Laser settings, number of IOP lowering medications were evaluated before treatment and after treatment at 2 weeks, 1 month, 3 months. Results: There were some relating factors for SLT outcome such as gender, trabecular pigment, pre-laser IOP. At 2 weeks after laser, success rate in male group was higher that female group $(p=0.013)$. At 3 months, higher pigmented group had higher success rate $(p=0.017)$. Similarly, at 1 month, higher pre-SLT IOP group got higher success rate $(p=0.013)$. There was no significant relation between age, duration of disease, number of IOP lowering medications, disease stage and treatment outcome. Conclusion: the significant impacting factors for SLT outcome on OAG eyes under medications were gender, pr-laser IOP and trabecular pigment.

Key words: POAG, SLT, IOP lowering medications

\section{I. ĐĂT VẤN ĐỀ}

Glôcôm là một trong những nguyên nhân hàng đầu gây mù lòa ở Việt Nam cũng như trên toàn thế giới. Bệnh gây tổn thương thần kinh thi giác không hồi phục và có thể dẫn đến mất thi lực hoàn toàn. Glốcôm góc mở nguyên phát là một tình trạng bệnh lý của thị thần kinh, tiến triển mạn tính, có sự kết hợp của nhiều yếu tố, đặc trưng bởi sự chểt của các tế bào hạch võng mạc, biểu hiện bằng tổn hại thị trường, lớp sợi thần kinh võng mạc và lõm teo đĩa thị giác. Lựa chọn hàng đầu trong điều trị glôcôm góc mở hiền nay vẫn là sử dung thuốc tra ha nhãn áp. Tuy nhiên, việc điều trị bằng thuốc có nhiều nhược điểm là giá thành cao, có thể gặp những tác dung phu của thuốc, đồng thời đòi hỏi người bênh phải tuân thủ điều trị thuốc mới đat hiêu quả duy trì nhãn áp ổn định. Phương pháp tạo hình vùng bè chọn lọc bằng laser được Latina và Park thực hiên lần đâuu vào năm 1995 đã cho thấy những ưu điểm nổi trội. Nhờ chỉ tác động chọn lọc lên các tế bào sắc tố mà không làm tổn thương các cấu trúc khác nên hạn chế tối đa các 
biến chứng của laser tao hình vùng bè․ Sau đó phương pháp này được chấp thuận bởi FDA vào năm 2002, được nhiều các tác giả trên thế giới áp dụng, thu được kết quả tốt. Với những bệnh nhân đã dùng thuốc tra ha nhãn áp, môt số tác giả cũng áp dụng điều trị cho kết quả thành công khá cao, giúp giảm chi phí do thuốc và thuận tiện cho bệnh nhân. Trên thế giới có nhiều nghiên cứu đánh giá mối liên quan giữa một số yếu tố của điều trị như: tuổi, giới, thời gian mắc bệnh, số thuốc trước điều trị, nhãn áp trước điều trị với kết quả điều trị tạo hình vùng bè choc loc bằng laser, nhằm đưa ra những chỉ định và tiển lượng phù hợp nhất cho bệnh nhân.

ở Việt Nam, cho đến nay kỹ thuật này mới chỉ áp dụng đơn lẻ và có một vài báo cáo sơ bộ về kết quả bước đầu của phương pháp tạo hình vùng bè chọn lọc bằng laser trên bệnh nhân glôcôm góc mở; chưa có nghiên cứu nào đánh giá các yếu tố liên quan đến kết quả điều trị. Vì vây, chúng tôi thực hiện đề tài này với muc tiêu nhận xét một số yếu tố liên quan đến kết quả điều trị tạo hình vùng bè chọn lọc bằng laser trên bệnh nhân glôcôm góc mở đã được điều trị bằng thuốc tra hạ nhãn áp.

\section{II. ĐỐI TƯợNG VÀ PHƯƠNG PHÁP NGHIÊN CỨU}

Đối tượng nghiên cứu. Những bệnh nhân được chẩn đoán là glôcôm góc mở nguyên phát, glôcôm thứ phát do thuốc $\geq 18$ tuổi; đã được điều trị bằng $\geq 02$ loại thuốc tra hạ nhãn áp; các môi trường trong suốt đủ để đánh giá tình trạng võng mạc; độ mở góc tiền phòng trung bình $\geq$ 3; đủ sức khỏe để cộng tác và đồng ý tham gia nghiên cứu; điều trị tại khoa Glôcôm Bệnh viện Mắt Trung Ương từ tháng 7/2019 đến tháng 7/2020. Các đối tượng loại trừ khỏi nghiên cứu: bệnh nhân có tiền sử chấn thương mắt; mắc các bệnh lý khác tại mắt như: bệnh giác mạc, đục thể thủy tinh, màng bồ đào, bệnh lý dịch kính võng mạc không cho phép đánh giá tình trạng võng mạc; các trường hợp đã được phẫu thuật nội nhãn và các bệnh nhân mắc hình thái glôcôm khác.

\section{Phương pháp nghiên cứu}

Thiết kế nghiên cứu. Nghiên cứu mô tả.

\section{Phương tiện nghiên cứu}

- Phương tiện phục vụ khám và đánh giá kết quả: bảng thị lực Snellen và hộp kính thử, sinh hiển vi đèn khe có gắn nhãn áp kế Goldmann, kính soi góc tiền phòng Goldmann 1 mặt gương, kính Volk soi đáy mắt, thị trường kế Humphrey, náy chụp OCT bán phần sau

- Phương tiện phục vụ điều trị: máy Ellex Tango - SLT/ YAG laser; kính Latina SLT gonio laser; chất nhầy; thuốc tra mắt: Dicain $1 \%$, Pilocarpin $1 \%$, Indocollyre $0,1 \%$.

\section{Cách thức nghiên cứu}

*Khám đánh giá trước điều tri: Bênh nhân được khám về chức năng, thực thể cũng như tình trạng toàn thân; khai thác tiền sử, bệnh sử.

*Kĩ thuâtt laser:

- Tra thuốc co đồng tử Pilocarpin $1 \%$ x 2 lần cách nhau 15 phút.

- Gây tê bề mặt bằng tra Dicain $1 \% \times 2$ lần cách nhau 5 phút.

- Đăt kính laser.

- Cài đă̆t thông số laser: kích thước vết đốt: $400 \mu \mathrm{m}$; thời gian: 3 nano giây; năng lượng: 0,4 $-1,4 \mathrm{~mJ}$.

Điều chỉnh hướng ánh sáng chùm tia laser vào vị trí giữa vùng bè sắc tố và vùng bè không sắc tố. Thường bắt đầu bằng năng lượng $0,8 \mathrm{~mJ}$ ở vùng bè có mức độ sắc tố bình thường (đô I và II theo Scheie), $0,6 \mathrm{~mJ}$ ở vùng bè có nhiều sắc tố (độ III và IV theo Scheie) và $1,0 \mathrm{~mJ}$ ở vùng vè không có sắc tố (độ 0 ). Tăng dân năng lượng cho đến khi thấy có các bot khí (nhỏ như bọt rượu sâm panh) thì giảm đi $0,1 \mathrm{~mJ}$ và tiếp tục laser ở mức năng lượng đó. Mỗi một phần tư chu vi vùng bè có thể cân điều chỉnh lại năng lượng phù hợp cho phù hợp với mức độ sắc tố của vùng bè. Các nốt laser được thực hiện liên tiếp, cạnh nhau đến khi bao phủ toàn bộ $180^{\circ}$ chu vi vùng bè. Thường là 50 nốt.

- Tháo kính laser và rửa mắt bằng dung dịch sát khuẩn hoặc kháng sinh.

- Sau 2 tuần bệnh nhân được chỉ định laser $180^{\circ}$ còn lại của chu vi vùng bè.

*Theo dõi - chăm sóc sau điều trị

- Dùng thuốc hạ nhãn áp Acetazolamid 0,25g $x 2$ viên/ ngày $x 2$ ngày sau khi laser.

- Thuốc chống viêm non-steroid tra mắt 4 lần/ ngày x 5 ngày

- Khám định kỳ tại các thời điểm sau điều trị 2 tuần, 1 tháng, 3 tháng, đánh giá tình trạng chức năng, thực thể; thị trường, OCT đánh giá tại thời điểm 3 tháng.

- Nếu bệnh tiến triển thể hiện bằng nhãn áp không đạt nhãn áp đích hoặc thị trường, đĩa thị tổn thương thêm thì bổ sung thêm thuốc tra ha nhãn áp cho đến khi đạt được nhãn áp đích, nếu vẫn không đạt được thì chuyển phẫu thuật.

*Đánh giá kết quả:

- Kết quả chức năng: thị lực (theo bảng phân loại của WHO 1999); thị trướng theo Hướng dẫn điều trị Glôcôm của Hội Glôcôm châu Âu (2014).

- Kết quả thực thể: nhãn áp (Goldmann); độ mở góc tiền phòng (phân loại của Shaffer); sắc 
tố góc tiền phòng (phân loại của Scheie).

- Đánh giá các biến chứng: cảm giác khó chịu, cộm vướng, tăng nhãn áp thoáng qua, viềm màng bồ đào...

- Đánh giá kết quả chung cuối cùng:

- Thành công: nhãn áp sau điều trị giảm $\geq$ $20 \%$ so với nhãn áp ban đầu hoặc giảm $\geq 1$ thuốc tra hạ nhãn áp so với số thuốc tra ban đầu; chức năng thị giác (thị lực, thị trường) ổn định hoặc tăng; tình trạng lõm teo đĩa thị giác ổn định.

- Không thành công: nhãn áp sau điêu trị giảm < $20 \%$ so với nhãn áp ban đầu hoặc phải dùng thêm thuốc, laser hoặc phẫu thuật; chức năng thị giác giảm (thị trường thu hẹp, thị lực giảm nhiều còn dưới 20/200); Iõm đãa tiến triển rộng thêm; có biến chứng nặng gây ảnh hưởng nhiều đên chức năng thị giác và sinh hoạt của bệnh nhân.

\section{KẾT QUẢ NGHIÊN CứU}

Bảng 1. Liên quan giữa nhóm tuổi và hiệu quả điều trị

\begin{tabular}{|c|c|c|c|c|c|c|}
\hline \multirow{2}{*}{ Nhóm tuổi } & \multicolumn{2}{|c|}{$\mathbf{2}$ tuân } & \multicolumn{2}{c|}{$\mathbf{1}$ tháng } & \multicolumn{2}{c|}{$\mathbf{3}$ tháng } \\
\cline { 2 - 7 } & $\begin{array}{c}\text { Thành } \\
\text { công }\end{array}$ & $\begin{array}{c}\text { Không } \\
\text { thành cồng }\end{array}$ & $\begin{array}{c}\text { Thành } \\
\text { công }\end{array}$ & $\begin{array}{c}\text { Không } \\
\text { thành cống }\end{array}$ & $\begin{array}{c}\text { Thành } \\
\text { Công }\end{array}$ & $\begin{array}{c}\text { Không } \\
\text { thành cống }\end{array}$ \\
\hline$<40$ & 10 & 1 & 8 & 3 & 5 & 1 \\
\hline $40-59$ & 9 & 7 & 16 & 0 & 15 & 1 \\
\hline$\geq 60$ & 9 & 4 & 12 & 1 & 10 & 1 \\
\hline Tống & $\mathbf{2 8}$ & $\mathbf{1 2}$ & $\mathbf{3 6}$ & $\mathbf{4}$ & $\mathbf{3 0}$ & $\mathbf{3}$ \\
\hline $\mathrm{p}$ & \multicolumn{3}{|c|}{0,187} \\
\hline
\end{tabular}

Có mối liên quan có ý nghĩa thống kê giữa giới tính và hiêu quả thành công của điều trị tai thời điểm 2 tuần $(p=0,013<0,05)$, trong đó tỷ lề thành công ở bệnh nhân nam cao hơn so với bênh nhân nữ. Tuy nhiên không có mối liên quan có ý nghĩa thống kê tại thời điểm 1 tháng và 3 tháng sau điều trị $(p>0,05)$.

Bảng 2. Liên quan giữa giới tính và hiệu quả điều trị

\begin{tabular}{|c|c|c|c|c|c|c|}
\hline Thời điếm & \multicolumn{2}{|c|}{2 tuân } & \multicolumn{2}{|c|}{1 tháng } & \multicolumn{2}{|c|}{3 tháng } \\
\hline Giới tính & \begin{tabular}{|c|} 
Không thành \\
cống
\end{tabular} & $\begin{array}{l}\text { Thành } \\
\text { công }\end{array}$ & \begin{tabular}{|c|} 
Không \\
thành cống
\end{tabular} & $\begin{array}{l}\text { Thành } \\
\text { công }\end{array}$ & $\begin{array}{c}\text { Không } \\
\text { thành cống }\end{array}$ & $\begin{array}{c}\text { Thành } \\
\text { công }\end{array}$ \\
\hline Nam & 3 & 19 & 2 & 20 & 1 & 16 \\
\hline Nữ & 9 & 9 & 2 & 16 & 2 & 14 \\
\hline Tống & 12 & 28 & 4 & 36 & 3 & 30 \\
\hline $\mathrm{p}$ & \multicolumn{2}{|c|}{$0,013^{*}$} & \multicolumn{2}{|c|}{0,99} & \multicolumn{2}{|c|}{0,601} \\
\hline
\end{tabular}

Thời gian mắc bệnh không có mối liên quan có ý nghĩa thống kê với thành công của điều trị tại các thời điểm sau điều trị $(p>0,05)$.

Số thuốc tra trước điều trị không có mối liên quan có ý nghĩa thống kê đến hiệu quả điều trị tại thời điểm 2 tuần, 1 tháng, 3 tháng $(\mathrm{p}>0,05)$.

Bảng 3. Liên quan giữa số thuốc tra đã sử dụng và hiệu quả điều trị

\begin{tabular}{|c|c|c|c|c|c|c|}
\hline \multicolumn{2}{|c|}{ Thời điểm Số thuốc tra } & 2 & 3 & 4 & Tổng & p \\
\hline \multirow{2}{*}{2 tuần } & Thành công & 4 & 14 & 10 & 28 & \multirow{2}{*}{0,083} \\
\hline & Không thành công & 6 & 4 & 2 & 12 & \\
\hline \multirow{2}{*}{1 tháng } & Thành công & 10 & 17 & 9 & 36 & \multirow{2}{*}{0,18} \\
\hline & Không thành công & 0 & 1 & 3 & 4 & \\
\hline \multirow{2}{*}{3 tháng } & Thành công & 9 & 16 & 5 & 30 & \multirow{2}{*}{0,751} \\
\hline & Không thành công & 1 & 1 & 1 & 3 & \\
\hline
\end{tabular}


Không có mối liên quan có ý nghĩa thống kê giữa thị lực trước điều trị và thành công của điều trị tại các thời điểm sau điều trị $(p>0,05)$.

Không có mối liên quan có ý nghĩa thống kê giữa nhãn áp trước điều trị với thành công của điều trị tại thời điểm 2 tuần, 3 tháng $(p>0,05)$.
Có mối liên quan có ý nghĩa thống kê giữa nhãn áp trước điều trị với thành công của điều trị tại thời điểm 1 tháng $(p<0,05)$ trong đó tỷ lệ thành công nhiều hơn ở nhóm có nhãn áp trước điều trị cao hơn.

Bảng 4. Liên quan nhãn áp trước điều trị và hiệu quả điều trị

\begin{tabular}{|c|c|c|c|}
\hline \multirow{2}{*}{ Thời điểm } & \multicolumn{2}{|c|}{ Nhãn áp (mmHg) } & \multirow{2}{*}{ p } \\
\cline { 2 - 3 } & Thành công & Không thành công & 0,083 \\
\hline 2 tuần & $28,68 \pm 5,6$ & $23,5 \pm 5$ & $0,013^{*}$ \\
\hline 1 tháng & $28,96 \pm 5,9$ & $24 \pm 4,41$ & 0,324 \\
\hline 3 tháng & $27,83 \pm 6,02$ & $25 \pm 5$ & \\
\hline
\end{tabular}

Không có mối liên quan có ý nghĩa thống kê giữa giai đoạn glôcôm với thành công điều trị tại thời điểm 2 tuần, 1 tháng và 3 tháng $(\mathrm{p}>0,05)$.

Bảng 5. Liên quan giai đoạn glôcôm và hiệu quả điều trị

\begin{tabular}{|c|c|c|c|c|c|c|}
\hline \multirow[b]{2}{*}{ Giai đoạn } & \multicolumn{2}{|c|}{2 tuần } & \multicolumn{2}{|c|}{1 tháng } & \multicolumn{2}{|c|}{3 tháng } \\
\hline & $\begin{array}{l}\text { Thành } \\
\text { công }\end{array}$ & $\begin{array}{c}\text { Không } \\
\text { thành cống }\end{array}$ & $\begin{array}{c}\text { Thành } \\
\text { công }\end{array}$ & $\begin{array}{c}\text { Không } \\
\text { thành cống }\end{array}$ & $\begin{array}{l}\text { Thành } \\
\text { công }\end{array}$ & $\begin{array}{c}\text { Không } \\
\text { thành cống }\end{array}$ \\
\hline Sớm & 3 & 2 & 5 & 0 & 4 & 0 \\
\hline Trung bình & 4 & 3 & 7 & 0 & 6 & 1 \\
\hline Nặng & 21 & 7 & 24 & 4 & 20 & 2 \\
\hline Tống & 28 & 12 & 36 & 4 & 30 & 3 \\
\hline$p$ & & 487 & & 749 & &, 99 \\
\hline
\end{tabular}

Có mối liên quan giữa tình trạng sắc tố vùng bè trước điều trị và tỷ lệ thành công điều trị tại thờ điểm 3 tháng sau điều trị $(p=0,017<0.05)$, trong đó sắc tố vùng bè càng cao càng làm tăng tỷ lệ thành công. Tuy nhiên không có mối liên quan có ý nghĩa thống kể tại thời điểm 2 tuần, 1 tháng ( $\mathrm{p}$ $>0,05$ ).

Bảng 6. Liên quan giữa sắc tố vùng bè và hiệu quả điều trị

\begin{tabular}{|c|c|c|c|c|c|c|c|}
\hline \multirow{2}{*}{\multicolumn{2}{|c|}{ Thời điểm }} & \multicolumn{2}{|c|}{2 tuần } & \multicolumn{2}{|c|}{1 tháng } & \multicolumn{2}{|c|}{3 tháng } \\
\hline & & Thành & Không & Thành & Không & Thành & Không \\
\hline \multirow{4}{*}{ Sắc tố } & 1 & 1 & 1 & 2 & 0 & 1 & 1 \\
\hline & 2 & 16 & 5 & 18 & 3 & 15 & 1 \\
\hline & 3 & 10 & 6 & 15 & 1 & 14 & 0 \\
\hline & 4 & 1 & 0 & 1 & 0 & 0 & 1 \\
\hline \multicolumn{2}{|c|}{ Tống } & 28 & 12 & 36 & 4 & 30 & 3 \\
\hline \multicolumn{2}{|c|}{$p$} & \multicolumn{2}{|c|}{0,604} & \multicolumn{2}{|c|}{0,724} & \multicolumn{2}{|c|}{$0,017^{*}$} \\
\hline
\end{tabular}

Không có mối liên quan có ý nghĩa thống kê giữa mức năng lượng laser và mức độ thành công của điều trị tại các thời điểm sau điêu trị $(p>0,05)$.

\section{BÀN LUÂN}

Nhóm nghiên cứu của chúng tôi có độ tuổi trung bình là 48,95 $\pm 15,76$; chúng tôi không tìm thây mối liên quan có ý nghĩa thống kê giữa tuổi và mức độ thành công của điều trị $(p>0,05)$. Trong nghiên cứu của Marcelo Ayala và cộng sự có tìm ra mối liên quan có ý nghĩa thống kê giữa mức độ thành công của SLT với tuổi, nhãn áp nền và tổng năng lượng laser ${ }^{2}$. Tuy nhiên độ tuổi trung bình của nghiên cứu này là rất cao: 76,5 và bệnh nhân chỉ được thực hiện laser SLT $90^{\circ}$, còn hầu hết các nghiên cứu khác điều trị bằng laser $180^{\circ}$ và $360^{\circ}$. Bệnh nhân cao tuổi thường mắc glôcôm giai đoạn trầm trọng hơn và bác sî khám cho bệnh nhân sau SLT có thể không cảm thấy hài lòng với mức ha nhãn áp này và thay đổi hướng điều trị do đó dẫn đến tăng số ca được phân loại thất baii. Trong một số nghiên cứu khác, ở nhóm bệnh nhân có độ tuổi thấp hơn như Gracner nghiên cứu trên bệnh nhân có độ tuổi trung bình là $70,3^{3}$, Hodge trên bệnh nhân có độ tuổi trung bình là $69,08^{4}$ và Mao thực hiện trên nhóm bệnh nhân có độ tuổi trung bình là $64^{5}$. Các tác giả đều không thấy có mối liên quan giữa tuổi và mức độ thành công sau điều trị SLT.

Về giới, chúng tôi tìm thấy mối liên quan có ý nghĩa thống kê giữa giới và mức độ thành công của điều trị tai thời điểm 2 tuần sau điều trị với tỷ lệ thành công cao hơn ở bệnh nhân nam. Tuy nhiển mối liên quan này không duy trì ở thời 
điểm 1 tháng và 3 tháng. Kết quả này tương đồng với nghiên cứu của các tác giả khác như Marcelo Ayala², Gracner và cộng sự ${ }^{3}$.

ở nhóm nghiên cứu của chúng tôi, số lượng thuốc tra trước điều trị cũng không có mối liên quan đến thành công điều trị tại thời điểm 2 tuần $(p=0,083>0,05), 1$ tháng $(p=0,18>$ $0,05)$ và 3 tháng $(p=0,751>0,05)$. Điêuu này gợi ý rằng SLT có thể phù hợp với những bệnh nhân đã dùng nhiều nhóm thuốc, cần thêm phương pháp điều trị bổ sung hoặc mong muốn giảm số thuốc tra hạ nhãn áp. Kết quả này tương đồng với nghiên cứu của các tác giả khác. Trái lại, có một số ít nghiên cứu như nghiên cứu của tác giả Lee và cộng sự cho thấy mối liên quan nghịch có ý nghĩa thống kê giữa dùng 3 loại thuốc hạ nhãn áp và hiệu quả điều trị $(\mathrm{p}=$ $0,037<0,05)^{8}$. Tuy nhiên nhóm nghiên cứu của tác giả trên bao gồm bệnh nhân glôcôm góc mở nguyên phát và glôcôm nhãn áp không cao với nhãn áp nền thấp hơn $20,30 \pm 4,64 \mathrm{mmHg}$, số thuốc tra hạ nhãn áp ở nhóm nhãn áp thấp cũng nhỏ hơn, chỉ có $1,72 \pm 1,03$ thuốc nên việc so sánh không hoàn toàn chính xác.

Có một số ít nghiên cứu khảo sát mối liên quan giữa thị lực ban đầu với thành công điều trị. Lee và cộng sự không tìm thấy mối liên quan giữa thị lực trước điều trị với thành công sau điều trị nhưng lại tìm thấy mới liên quan có ý nghĩa thống kê giữa tật khúc xạ và thành công của điều trị, tật khúc xạ càng cao tỷ lệ thành công càng $\mathrm{cao}^{8}$. Nghiên cứu của chúng tôi cũng cho kết quả tương tự khi không tìm ra mối liên quan giữa mức thị lực ban đâu và thành công điều trị $(p>0,05)$.

Nhã̃n áp nền trước điều trị là yếu tố được hầu hết các tác giả khảo sát để tiên lượng hiệu quả điều trị của SLT. Nghiên cứu của chúng tôi tìm thấy mối liên quan có ý nghĩa thống kê giữa nhãn áp nền với thành công của điều trị tại thời điểm 1 tháng sau SLT $(p<0,05)$, trong đó nhãn áp trước điều trị càng cao thì tỷ lệ thành công của điều trị càng cao. Mặc dù vậy ở thời điểm 3 tháng chúng tôi lại không thây sự liên quan có ý nghĩa giữa hai yếu tố này. Điều này có thể do số lượng bênh nhân trong nhóm nghiên cứu của chúng tôi còn ít, số lượng bệnh nhân tại thời điểm 3 tháng giảm đi so với thời điểm 1 tháng. Gracner và cộng sự cũng không tìm thấy mối liên quan có ý nghĩa thống kê giữa nhãn áp nền và thành công điều trị có lẽ do mức nhãn áp khác nhau giữa các bệnh nhân được đề cập đến ${ }^{3}$. Tuy nhiên có nhiều nghiên cứu tìm thấy mối liên quan giữa nhãn áp nền và thành công của điều trị. Mao và công sự tìm thấy tỷ lệ thành công cao hơn ở nhóm bệnh nhân có nhãn áp nền 26 $\mathrm{mmHg}$; nhãn áp nền thấp có hiệu quả hạ nhãn áp thấp hơn ${ }^{5}$. Điều này cũng được ghi nhận bởi tác giả Hodge và công sự khi thực hiện thử nghiệm lâm sàng ngẫu nhiên đánh giá mức độ thành công của SLT sau 1 năm điêuu trị dựa vào nhãn áp nền ${ }^{4} ;$ nghiên cứu của Hirabayashi và cộng sự trên nhóm 252 mắt của198 bệnh nhân, cho thấy mối liên quan thuận có ý nghĩa thống kê giữa nhãn áp nền với thành công chung của điều trị $(p<0,001)^{6}$. Laser SLT giúp giảm trở lưu tại vùng bè, tăng thoát thủy dịch do vậy mức độ hạ nhãn áp có thể phụ thuộc vào áp lực nội nhãn ban đầu và áp lực càng cao thì mức độ hạ nhãn áp càng lớn.

Trong nhóm nghiên cứu của chúng tôi không tìm ra mối liên quan có ý nghĩa thống kê giữa giai đoạn glôcôm góc mở với thành công điều trị tại thời điểm 2 tuần, 1 tháng, 3 tháng sau SLT ( $p$ $>0,05)$. Kết quả này tương đồng với tác giả Hirabayashi và cộng sự, trong nhóm nghiên cứu 252 mắt: có $43,3 \%$ mắt ở giai đoạn nhẹ, $18,6 \%$ mắt ở giai đoạn trung bình và $38,1 \%$ mắt ở giai đoạn nặng, không tìm thấy mối liên quan có ý nghĩa thống kê giữa giai đoạn glôcôm và thành công điều trị $(p=0,668>0,05)^{6}$. Tác giả Kuley và cộng sự nghiên cứu trên mấu 997 mắt từ 677 bệnh nhân cũng cho kết quả tương tự $(p=0,99$ $>0,05)^{9}$. Như vậy, giai đoạn glôcôm không phải là yếu tố liên lượng thành công của điều trị, những bệnh nhân giai đoạn nặng vẫn có thể được chỉ định điều trị bằng SLT.

Về mức độ sắc tố của vùng bè, chúng tôi cũng không thây có mối liên quan với mức độ thành công của điều trị ở thời điểm 2 tuần và 1 tháng. Nhưng lại có mối liên quan ở thời điểm 3 tháng. Tỷ lệ thành công cao hơn ở nhóm có sắc tố vùng bè độ 2 và 3 . Trong nghiên cứu của tác giả Matthew Hirabayashi và cộng sự cũng cho thấy không có mối liên quan có ý nghĩa thống kê giữa sắc tố góc tiền phòng và thành công điều trị $(p=0,494>0,05)^{6}$. Điều này cũng được khằng định trong các nghiên cứu trước đó của Hodge và cộng sự ; Mao và cộng sự ${ }^{5}$. Trái lại, tác giả Gracner và cộng sự ghi nhận mối liển quan có ý nghĩa thống kê giữa sắc tố vùng bè và mức độ thành công của điều trị $(p=0,01<$ $0,05)^{3}$, sắc tố vùng bè càng nhiều thì tỷ lệ thành công càng thấp. Sắc tố tại vùng bè có thể ảnh hưởng đến khả năng hấp thụ năng lượng laser và quá trình đại thực bào dọn dẹp lưới bè sau đó. Điều này có thể giải thích sự khác biệt về tỷ lệ thành công muộn sau 3 tháng ở nhóm sắc tố 
cao hơn do lưới bè cần thời gian để hồi phục hoàn toàn sau điều trị.

\section{KẾT LUÂ̂N}

Nghiên cứu của chúng tôi cho thấy có mối liên quan giữa giới tính, sắc tố vùng, nhãn áp trước điều trị với thành công điều trị. Không có mối liên quan có ý nghĩa thống kê giữa tuổi, thời gian mắc bệnh, số thuốc tra hạ nhãn áp trước điều trị, giai đoạn bệnh, năng lượng laser đến thành công của điều trị.

\section{TÀI LIÊU THAM KHẢO}

1. Anderson RR, Parish JA. Selective photothermolysis: Precise microsurgery by selective absorption of pulsed radiation. Science 1983 Apr;220(4596):524-527.

2. Ayala $\mathbf{M}$, Chen $\mathbf{E}$. Predictive factors of success in selective laser trabeculoplasty (SLT) treatment. Clin Ophthalmol. 2011;5:573-576. doi:10.2147/ OPTH.S19873

3. Gracner T, Naji M, Hudovernik M, Gracner B, Pahor D. [Predictive factors of successful selective laser trabeculoplasty in open-angle glaucoma]. Klin Monbl Augenheilkd. 2007;224(12):922-926. doi:10.1055/s-2007-963744

4. Hodge WG, Damji KF, Rock W, Buhrmann R,
Bovell AM, Pan Y. Baseline IOP predicts selective laser trabeculoplasty success at 1 year posttreatment: results from a randomised clinical trial. British Journal of Ophthalmology. 2005;89 (9):1157-1160. doi:10.1136/bjo.2004.062414

5. Mao AJ, Pan XJ, McIlraith $I$, Strasfeld $M$, Colev G, Hutnik C. Development of a prediction rule to estimate the probability of acceptable intraocular pressure reduction after selective laser trabeculoplasty in open-angle glaucoma and ocular hypertension. J Glaucoma 2008 Sep;17(6):449-454.

6. Hirabayashi M, Ponnusamy V, An J. Predictive Factors for Outcomes of Selective Laser Trabeculoplasty. Sci Rep. 2020;10. doi:10.1038/s41598-020-66473-0

7. Pillunat KR, Spoerl E, Elfes G, Pillunat LE. Preoperative intraocular pressure as a predictor of selective laser trabeculoplasty efficacy. Acta Ophthalmologica. doi:10.1111/aos.13094

8. Lee JWY, Liu CCL, Chan JCH, Lai JSM. Predictors of success in selective laser trabeculoplasty for chinese open-angle glaucoma. J Glaucoma. 2014; 23(5):321-325. doi: 10.1097/ IJG.0000000000000049

9. Kuley B, Zheng CX, Zhang $Q$ (Ed), et al, Predictors of Success in Selective Laser Trabeculoplasty. Ophthalmology Glaucoma. 2020;3 (2):97-102. doi:10.1016/j.ogla.2019.11.010

\section{ĐÁNH GIÁ KẾT QUẢ PHẪU THUÂT VÁ THỦNG VÁCH LIÊN THẤT SAU NHỒI MÁU CO' TIM}

\section{TÓM TẮT}

Mở đâu: Thủng vách liên thất là môt biến chứng nặng và ít gặp của nhồi máu cơ tim cấp. Bệnh nhân không điều trị phẫu thuật có tỉ lệ tử vong cao. Có nhiều loai phẫu thuật điều trị bệnh lý này, trong đó có vá lỗ thủng vách liển thất bẳng kĩ thuật hai miếng vá qua đường mở thất phải. Đề tài nhằm muc tiêu đánh giá kết quả của phẩu thuật điều trị thủng vách liên thất sau nhồi máu cơ tim bằng phương pháp hai miếng vá qua đường mở thất phải. Đối tượng Phương pháp nghiên cứu: Hồi cứu, mô tả loạt ca được phẫu thuật vá lỗ thủng vách liên thất bằng phương pháp hai miếng vá qua đường mở thất phải tại Bệnh viện Chợ Rẫy từ tháng 01/2014 đến tháng $01 / 2020$. Kết quả: Từ tháng $01 / 2014$ đến tháng 01/2020, chúng tôi sử dụng phương pháp vá lỗ thông liên thất bằng hai miếng vá cho 36 bệnh nhân. Tuổi trung bình của các bệnh nhân là $67,2 \pm 11,4$ tuổi. Có 28 bệnh nhân là nam, chiếm 77,8\%. Thời gian kẹp

*Trung tâm Tim - Mạch bệnh viện Chợ Rẫy.

Chịu trách nhiệm chính: Trần Quyết Tiến

Email: tienchoray@yahoo.com

Ngày nhận bài: 25.01.2021

Ngày phản biên khoa họ: 19.3.2021

Ngày duyệt bài: 29.3.2021
Trần Quyết Tiến*

động mạch chủ trung bình 97,4 phút. Thời gian chạy tuần hoàn ngoài cơ thể trung bình 146,2 phút. Tỉ lệ tử vong sớm là $22,2 \% ; 3$ trường hợp tai biến mạch máu não, 4 trường hợp chảy máu cần mổ lại, 5 trường hợp suy thận cần chạy thận nhân tạo. 1 trường hợp tử vong trung hạn vì nhồi máu cơ tim tái phát. Kết luận: Phẫu thuật vá thủng vách liên thất sau nhồi máu cơ tim bằng kĩ thuật hai miếng vá an toàn, hiệu quả và có kết quả trung han tốt. Kî thuật có ưu điểm là đơn giản, ít khả năng tái phát thông liên thất và có thể áp dụng được cho cả thủng vách liên thất phía trước và phía sau.

\section{SUMMARY \\ THE SURGICAL TREATMENT RESAULT OF VENTRICULAR SEPTAL DEFECT DUE TO MYOCARDIAL INFARCTION}

Introduction: Ventricular septal perforation is a serious and uncommon complication of acute myocardial infarction. Patients without surgical treatment have a high mortality rate. There are many types of surgery to treat this disease, including twopatch technique through the right ventriculotomy. The research aims to evaluate the results of surgery for the treatment of ventricular septal perforation after myocardial infarction by the two-patch technique. Methods: This is a retrospective case series of 